\title{
Adult male southern elephant seals from King George Island utilize the Weddell Sea
}

\author{
C.A. TOSH ${ }^{1 *}$, H. BORNEMANN ${ }^{2}$, S. RAMDOHR ${ }^{2}$, M. SCHRÖDER ${ }^{2}$, T. MARTIN ${ }^{3}$, A. CARLINI ${ }^{4}$, \\ J. PLÖTZ ${ }^{2}$ and M.N. BESTER ${ }^{1}$ \\ ${ }^{1}$ Mammal Research Institute, Department of Zoology and Entomology, University of Pretoria, Pretoria 0002, South Africa \\ ${ }^{2}$ Alfred Wegener Institute for Polar and Marine Research, Postfach 120161, D-27515 Bremerhaven, Germany \\ ${ }^{3}$ Leibniz-Institute of Marine Sciences, IFM-GEOMAR, Düsternbrooker Weg 20, D-24105 Kiel, Germany \\ ${ }^{4}$ Instituto Antártico Argentino, Departamento de Ciencias Biológicas, Cerrito 1248, 1010 Buenos Aires, Argentina \\ *catosh@zoology.up.ac.za
}

\begin{abstract}
Adult male southern elephant seals instrumented in 2000 on King George Island ( $n=13)$, travelled both to the north $(n=2)$ and to the east $(n=6)$ of the Antarctic Peninsula. Five males remained within $500 \mathrm{~km}$ of the island focusing movements in the Bransfield Strait and around the Antarctic Peninsula. Sea surface temperatures encountered by these animals showed little variation. While animal trajectories appeared unaffected by sea ice cover, areas of shallow depths were frequented. Three males moved as far as $75^{\circ} \mathrm{S}$ to the east of the Peninsula with maximum distances of more than $1500 \mathrm{~km}$ from King George Island. They travelled into the Weddell Sea along the western continental shelf break until they reached the region of the Filchner Trough outflow. Here the sea floor consists of canyons and ridges that support intensive mixing between the warm saline waters of the Weddell Gyre, the very cold outflow waters and ice shelf water at the Antarctic Slope Front. The need for re-instrumentation of adult males from King George Island is highlighted to investigate whether males continue to travel to similar areas and to obtain higher resolution data.
\end{abstract}

Received 22 April 2008, accepted 28 July 2008

Key words: Antarctic Peninsula, area restricted movements, post-moult movements, satellite telemetry, sea ice

\section{Introduction}

In the last decade, studies of animal movements have provided insights into previously unexplored aspects of behaviour, ecology and biology (Schaffer et al. 2006). New technologies have provided data that facilitate the development of management actions and conservation of endangered species (Lombard et al. 2007). The use of animal movement data remains tentative for conservation applications in marine habitats, possibly due to the difficulty in establishing effective marine conservation areas (Sale et al. 2005), the quantification of marine habitat types (Gregr \& Bodtker 2007), and the lack of multidisciplinary integration necessary for making wider management decisions. The study of marine top predators in relation to their physical environment may aid in marine conservation and provide a basis for further ecological studies. Southern elephant seals are top predators in Antarctic ecosystems and knowledge of their foraging ranges will aid in understanding their impacts within the Southern Ocean, as well as shedding light on the influences of oceanographic factors on higher order organisms.

Southern elephant seals have been tracked from South Georgia (McConnell et al. 1992, McConnell \& Fedak 1996), Iles Kerguelen (Bailleul et al. 2007), Macquarie
Island (Hindell et al. 1991, van den Hoff et al. 2002, Hindell et al. 2003) and Peninsula Valdés (Campagna et al. 2000, 2006, 2007). These large populations make up the major stocks of southern elephant seals worldwide and are augmented by populations from smaller surrounding islands. Southern elephant seals from King George Island form part of the South Georgia stock of elephant seals. Southern elephant seals from the South Georgia and Peninsula Valdés stocks have not declined in recent years (McMahon et al. 2005). The decline in stocks from other populations has been attributed to declines in juvenile and/ or adult female survival, possibly due to limited food availability (Pistorius et al. 2004, McMahon et al. 2005). Southern elephant seal numbers on King George Island have remained stable for some time (SCAR 2000), although a decline has been noted in recent years (Carlini personal communication 2007). This population is characterized by heavier pups at weaning (Carlini et al. 1997) and larger females that show higher rates of mass gain whilst spending shorter periods at sea (Carlini et al. 2005) when compared to other populations. Ocean habitat usage of female and under-yearling elephant seals from South Georgia and King George islands are generally in the area west of the Antarctic Peninsula (McConnell et al. 
1992, McConnell \& Fedak 1996, Bornemann et al. 2000). Movements in relation to sea ice have also reportedly varied, with juvenile elephant seals avoiding sea ice and adult females frequenting the outer ice fringe or venturing into thick pack ice (Bornemann et al. 2000).

Southern elephant seals from different populations encounter different oceanic environments (Biuw et al. 2007). On a broad scale, frontal systems and major bathymetric features seem to play an important role for elephant seal populations on sub-Antarctic islands situated at higher latitudes, e.g. Marion Island (Jonker \& Bester 1998), Macquarie Island (Hindell et al. 1991, Field et al. 2001, Hindell et al. 2003) and Peninsula Valdés (Campagna et al. 2000). Movement patterns of male and female elephant seals have also been shown to differ at fine and coarse resolutions (Hindell et al. 1991, Campagna et al. 1999, Le Boeuf et al. 2000, Bailleul et al. 2007). Many of these studies rely on the use of geolocators which record light level, as positioning devices, which only allow for broad-scale studies (Bradshaw et al. 2002). Finer-scale studies, made possible by newer technologies (Fedak 2004, Block 2005) that include transmitters with higher resolution capabilities with the ability to measure oceanographic variables in situ (Biuw et al. 2007), as well as the availability of higher resolution auxiliary data, have shown that southern elephant seals make use of transient temperature fronts, such as eddies (Campagna et al. 2006) and ever-changing ice edge dynamics (Bornemann et al. 2000, Bailleul et al. 2007), and have highlighted the individual variation that exists at meso-scales (Campagna et al. 2007).

Adult male southern elephant seals compete to enhance their reproductive success, with larger males being more successful due to an ability to spend longer periods on land and to obtain a central position in the harem (McCann 1981). At Marion Island, breeding males fast for approximately three months of the year whilst expending energy in competitive behaviour and in multiple breeding events (Wilkinson \& Bester 1990). Females come into oestrus shortly before the pups wean, and multiple copulation events occur shortly before the females leave to forage (Le Boeuf \& Laws 1994). These extreme breeding events require great energy expenditure (Galimberti et al. 2007) and have ultimately resulted in a shortened life span, an average of 10-12 years in contrast with females that have longevity of 22 years (Hindell \& Little 1988) and non-breeding males that can live up to 20 years (LeBoeuf \& Laws 1994). The breeding success of a male that hauls out to breed is also not ensured, with males forming a complex hierarchical structure that does not guarantee mating opportunities (McCann 1981).

It is possible that the movement patterns of adult males are in response to the intensive and energy depleting acts of breeding and moulting - a thirty-day period during which elephant seals replace their entire pelage (Le Boeuf \& Laws 1994). Future survival and reproductive success is thus dependent upon blubber stores accumulated during successful foraging. The large body size of adult male southern elephant seals could possibly have two-fold advantages: in addition to the ability of larger animals to fast for longer durations, larger animals may also have the ability to utilize a variety of oceanic habitats that are inaccessible to smaller bodied female and juvenile animals. The ability to adopt varied diving strategies and the need to maximize foraging success may drive observed variations in foraging strategies (Le Boeuf et al. 2000).

This study presents data showing the movements of adult males from the King George Island population of southern elephant seals. A preliminary method for quantifying movement variation is also presented. Individual variation in movements is shown. Evidence of the utilization of the area to the south-east of the Peninsula, and particularly to a highly specific area in the southern Weddell Sea, a previously unobserved pattern (Biuw et al. 2007), is presented.

\section{Methods}

Fifteen adult male ( $\geq 6$ years old) southern elephant seals were instrumented between March and April 2000 at Stranger Point, King George Island $\left(62^{\circ} 14^{\prime} \mathrm{S}, 58^{\circ} 40^{\prime} \mathrm{W}\right)$ (Fig. 1a \& b). This work follows on an earlier project that entailed the instrumentation of 13 adult females and seven under-yearling seals (Bornemann et al. 2000).

All the animals were instrumented with satellite-linked depth recorders (SDR T-6 or SDR T-10 Wildlife Computers, Redmond, WA, USA). These two transmitter types were designed to provide processed data on the locations and diving behaviour (maximum depth, dive duration, dive depth frequency and time-at-depth) in the form of 6-hourly histograms. The transmitters varied in the resolution of dive measurements that were taken. The present paper focuses specifically on location data, and the dive data is not discussed. The transmission protocol of location data was exactly the same for both transmitter types, transmitting data at $90 \mathrm{sec}$ intervals between $00 \mathrm{~h} 00$ (GMT) and 23h00 (GMT) when animals were at the surface.

The immobilization procedure used in this study has been described elsewhere (Ramdohr et al. 2001). Animals were first remotely darted using automatically evacuating syringes (Telinject, Römerberg, Germany) filled with Large Animal (LA) Immobilon to achieve initial immobilization. Ketamine hydrochloride was subsequently administered intramuscularly by hand to maintain immobilization. Both the dosage, and the number of injections of ketamine was determined by the stage of narcosis (Ramdohr et al. 2001). The transmitters were attached using a star-shaped gauze mat that was glued onto the head of the animal using quicksetting epoxy resin (Bornemann et al. 2000).

Incoming ARGOS data was decoded using SatPack software (Wildlife Computers). Location data of all quality classes were filtered according to a $10 \mathrm{~km} \cdot \mathrm{h}^{-1}$ velocity 
a

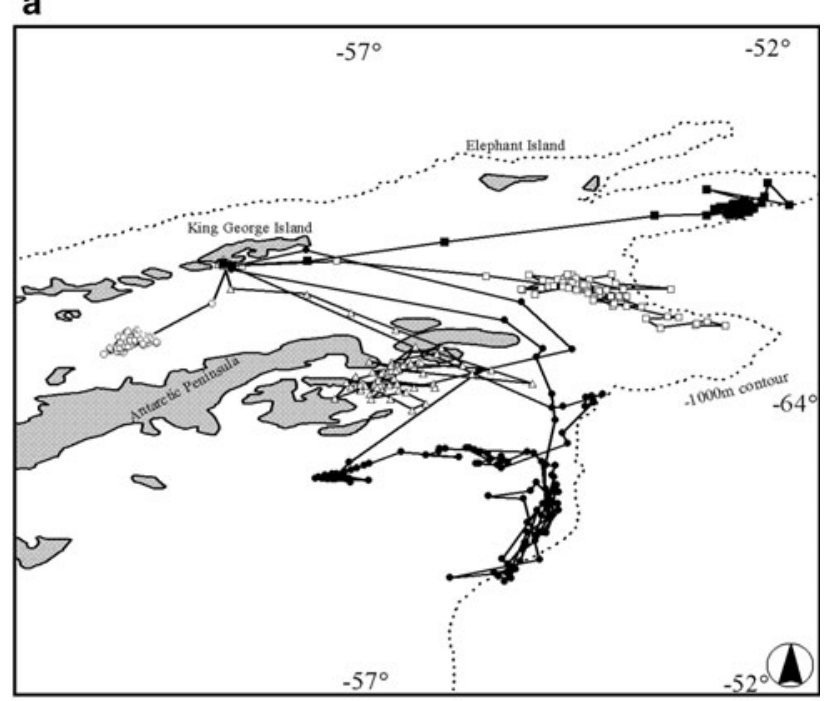

b

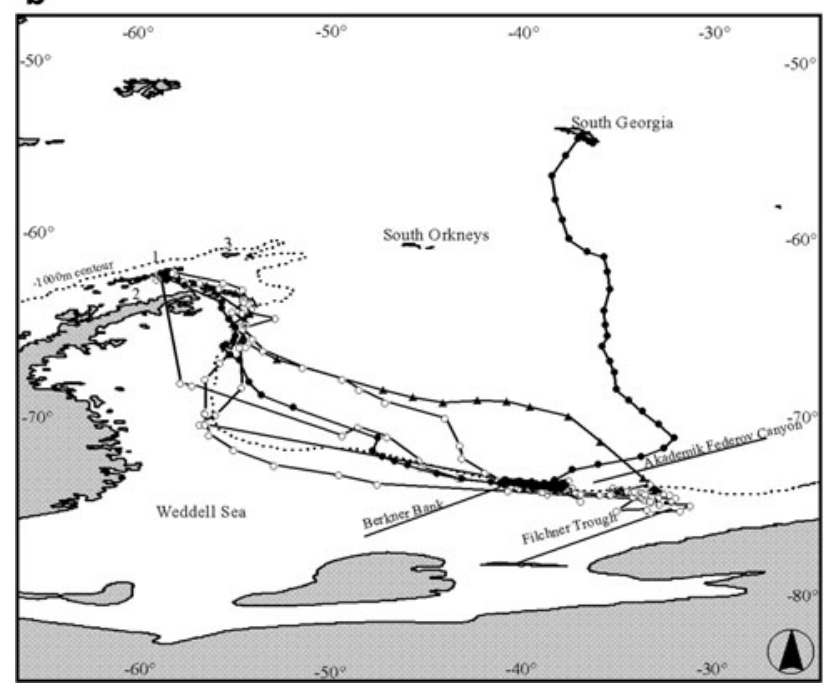

Fig. 1. The tracks of adult male southern elephant seals (Mirounga leonina) from King George Island (1) instrumented in 2000.

a. The tracks of AM3 $(-\circ), \operatorname{AM} 6(--), \operatorname{AM} 8(--), \operatorname{AM} 11$ (- - ) and AM13 (- $\square-$ ). These animals spent extended periods of time in close proximity to King George Island. b. Tracks of AM9 (- - ), AM10 ( $\boldsymbol{-}-)$, and AM14 (- - ) locations were recorded from April 2000 to February 2001. King George Island (1), the Bransfield Strait (2) and Elephant Island (3) as well as major bathymetric features in the Weddell Sea are indicated on the map.

algorithm (McConnell et al. 1992) which removes locations requiring unrealistic swimming speeds of greater than $10 \mathrm{~km} \cdot \mathrm{h}^{-1}$. All the locations were averaged to a daily location to provide regular trajectories over time. All locations, regardless of location quality, were used because long range movements $(>10 \mathrm{~km})$ were analysed (White \& Sjöberg 2002). All primary data derived from ARGOS locations are archived and available in open access through the data library PANGAEA-Publishing Network for
Geoscientific and Environmental data (http://doi:pangaea. de/10.1594/PANGAEA.692856). Of the 14 instrumented animals, only eight animals were tracked for more than 40 days (mean transmission time $=112$ days; range $=8-338$ days). These tracks were retained in the analysis to give an overall impression of habitat usage by these animals due to the fact that they included at least one transit phase and one area of restricted movement.

Individual tracks were analysed separately to identify area restricted movement (ARM) as opposed to transit movements. By choosing the animal as a sampling unit, issues of pseudo-replication that arise from the use of locations as sampling units were avoided (Otis \& White 1999). A simple analysis of the cumulative distance from the origin of the track was performed to identify areas of restricted movement. As time-constrained central place foragers, southern elephant seal tracks are characterized by a spatially discrete area of altered activity flanked by direct transit phases (e.g. McConnell et al. 1992, McConnell \& Fedak 1996, Jonker \& Bester 1998, Campagna et al. 2007). Area restricted movement was defined as all the consecutive locations that displayed a minimum variability in terms of distance from the origin of the track that were flanked by transit movements, which had high variability in terms of distance from the origin of the track (Fig. 2). Although relatively crude and subjective to directional bias, this method is adequate for this set of location data which present very clear distinctions between periods of travel to and from such areas. In order to rank the degree of restriction displayed in movements, an index of movement variability (MV) was created for each segment of each track:

$$
M V\{n: 1)\}=S D\{n: 1\} / \text { no.days }\{n: 1\}
$$

where $S D$ is the standard deviation in distance from the point of origin, in this case King George Island and no. days is the number of days spent in a specific sector of movement $(n: 1)$. Quantifying movement variation in this way was deemed suitable for tracks where segments of area restricted movement were clearly delineated.

Elephant seal locations were overlaid onto meso-scale environmental data. Bathymetric data, including sea floor depth and bathymetric feature names, were obtained from the GEBCO Digital Atlas (IOC 2003). The data were interpolated to a $25 \mathrm{~km} \times 25 \mathrm{~km}$ grid, the same as the sea ice data obtained by the Special Sensor Microwave Imager $(\mathrm{SSM} / \mathrm{I})$ satellite, as retrieved by the NASA-TeamAlgorithm (Cavalieri et al. 1996). The average rate of travel for all the animals in this study was $20 \mathrm{~km} \mathrm{day}^{-1}$, making comparisons at this resolution reasonable because the resolution of the auxiliary data is the same as the resolution of the track data. All elephant seal locations were interpolated to monthly sea ice values in order to highlight seasonal variability in sea ice concentrations for the locations considered in this study. Weekly optimally 

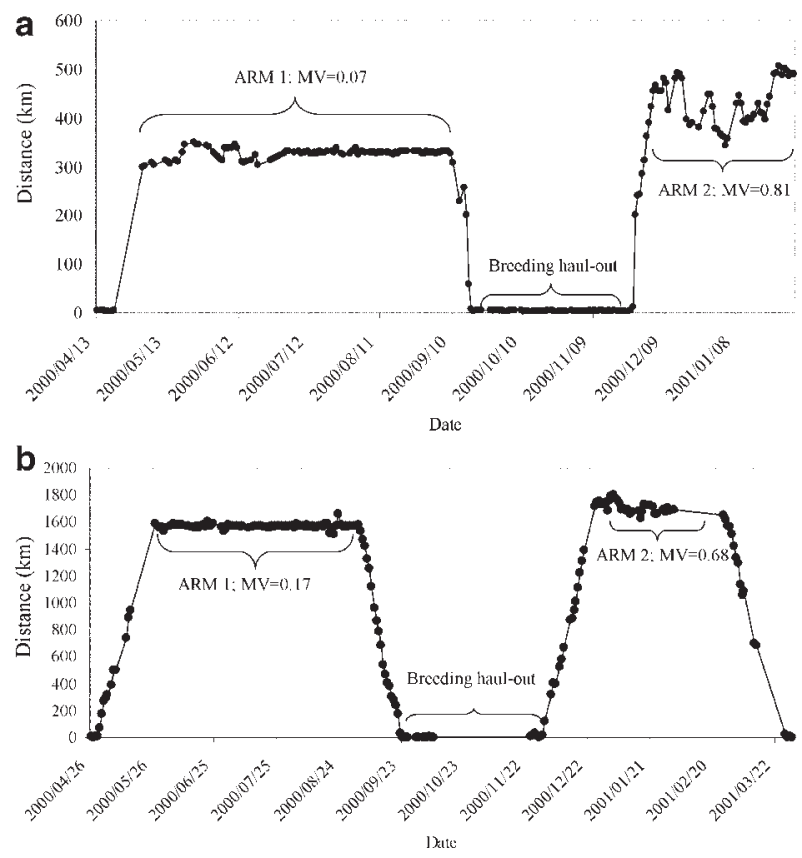

Fig. 2. Distance $(\mathrm{km})$ from King George Island over time for a. AM11, and b. AM14, indicating the movement variation (MV) during the post-moult area of restricted movement (ARM1) and the post-breeding area of restricted movement (ARM2).

integrated sea surface temperatures (OISST) were also interpolated to the elephant seal locations. These data are supplied in the corrected format (ftp://oceans.gsfc.nasa.gov/ OISST) and are derived from in situ, satellite and sea ice simulated sea surface temperatures (Reynolds et al. 2002).

\section{Results}

Eight animals provided tracks of more than 40 days; these tracks were retained in the analysis in order to represent at least one transit phase and one area of restricted movement for each animal. The duration of the selected tracks varied between 48 days and 338 days, with only two animals providing tracks that were shorter than 100 days. All of these animals displayed area restricted movements (ARM) at some point during their tracks. Basic movement parameters, environmental values encountered during tracking, and average movement variations for areas of restricted movements and transit locations are presented in Table I.

Area restricted movement indices (MV) varied substantially between animals, with AM10 displaying the largest $\mathrm{MV}=1.48 \mathrm{~km} \mathrm{day}^{-1}$ and $\mathrm{AM} 3$ displaying the smallest $\mathrm{MV}=0.05 \mathrm{~km} \mathrm{day}^{-1}$ during its only period of ARM. MV values during transit varied between $25.93 \mathrm{~km}$ day $^{-1}$ (AM8) and $7.14 \mathrm{~km} \mathrm{day}^{-1}$ (AM3) (Table I). Two animals had more than one area of restricted movement. AM11 and AM14 both returned to King George Island for the breeding season and retained their transmitters during the post-breeding trip. MV values, for both animals, were greater for the areas of restricted movement after the breeding period than after the moult (Fig. 2).

Individual movements varied considerably, with maximum distances from King George Island varying between $156 \mathrm{~km}$ (AM3) and $1800 \mathrm{~km}$ (AM14) and total trip distances varying between $850 \mathrm{~km}$ (AM3) and 10 $782 \mathrm{~km}$ (AM14).

One animal (AM3) spent 4.8 months in the Bransfield Strait, no further than $156 \mathrm{~km}$ from King George Island

Table I. Standard length, basic location statistics, average values and standard deviations (SD) of environmental variables encountered and movement variation indices (Areas of Restricted Movement $=$ ARM) for the adult male southern elephant seals $(n=8)$ instrumented during March and April 2000 at King George Island.

\begin{tabular}{|c|c|c|c|c|c|c|c|}
\hline Seal & $\begin{array}{l}\text { Standard } \\
\text { length }(\mathrm{m})\end{array}$ & $\begin{array}{c}\text { Date of } \\
\text { deployment }\end{array}$ & $\begin{array}{c}\text { Track } \\
\text { duration }(\mathrm{d})\end{array}$ & $\begin{array}{l}\text { No. locations } \\
\text { (n) }\end{array}$ & Haulout & $\begin{array}{l}\text { Maximum distance from } \\
\text { King George Island }(\mathrm{km})\end{array}$ & $\begin{array}{l}\text { Total distance } \\
\text { travelled }(\mathrm{km})\end{array}$ \\
\hline AM3 & 3.9 & $09 / 03 / 2000$ & 146 & 131 & & 155.80 & 849.27 \\
\hline AM6 & 3.9 & $18 / 03 / 2000$ & 100 & 89 & & 264.42 & 1797.27 \\
\hline AM8 & 4.32 & $31 / 03 / 2000$ & 136 & 126 & & 378.98 & 1279.45 \\
\hline AM9 & 4.6 & $07 / 04 / 2000$ & 197 & 165 & South Georgia ${ }^{B}$ & 1582.27 & 5129.91 \\
\hline AM10 & 4.3 & $12 / 04 / 2000$ & 48 & 30 & & 1715.49 & 2000.25 \\
\hline AM11 & 4.2 & $12 / 04 / 2000$ & 294 & 225 & King George Island ${ }^{\mathrm{B}}$ & 505.98 & 3420.63 \\
\hline AM13 & 4.05 & $21 / 04 / 2000$ & 92 & 89 & & 332.48 & 1463.96 \\
\hline AM14 & 4.38 & $21 / 04 / 2000$ & 338 & 203 & King George Island ${ }^{\mathrm{B} \& \mathrm{M}}$ & 1799.59 & 10781.53 \\
\hline & \multicolumn{2}{|c|}{$\begin{array}{l}\text { Sea Ice }[\%] \\
\text { Mean } \pm \text { SD }\end{array}$} & \multicolumn{2}{|c|}{$\begin{array}{c}\text { Bathymetry (m) } \\
\text { Mean } \pm \text { SD }\end{array}$} & $\begin{array}{l}\text { Sea surface temperature } \\
\quad\left({ }^{\circ} \mathrm{C}\right) \text { Mean } \pm \mathrm{SD}\end{array}$ & $\begin{array}{c}\text { Movement } \\
\text { variation }_{\mathrm{ARM}}\end{array}$ & $\begin{array}{c}\text { Movement } \\
\text { variation }_{\text {Transit }}\end{array}$ \\
\hline AM3 & \multicolumn{2}{|c|}{$0.47 \pm 3.82$} & \multicolumn{2}{|c|}{$-315.15 \pm 235.09$} & $-1.66 \pm 0.5$ & 0.05 & 7.14 \\
\hline AM6 & \multicolumn{2}{|c|}{$21.07 \pm 21.27$} & \multicolumn{2}{|c|}{$-288.88 \pm 275.93$} & $-1.61 \pm 0.36$ & 0.23 & 8.64 \\
\hline AM8 & \multicolumn{2}{|c|}{$19.86 \pm 19.74$} & \multicolumn{2}{|c|}{$-500.06 \pm 280.98$} & $2.58 \pm 1.87$ & 0.07 & 25.93 \\
\hline AM9 & \multicolumn{2}{|c|}{$82.13 \pm 34.21$} & \multicolumn{2}{|c|}{$-1284.33 \pm 1212.57$} & $-1.47 \pm 0.91$ & 0.25 & 12.14 \\
\hline AM10 & \multicolumn{2}{|c|}{$70.67 \pm 40.87$} & \multicolumn{2}{|c|}{$-1735.47 \pm 1534.94$} & $0.01 \pm 1.63$ & 1.48 & 15.98 \\
\hline AM11 & \multicolumn{2}{|c|}{$60.61 \pm 37.61$} & \multicolumn{2}{|c|}{$-385.60 \pm 269.78$} & $-1.39 \pm 0.56$ & 0.44 & 12.38 \\
\hline AM13 & \multicolumn{2}{|c|}{$38.03 \pm 20.21$} & \multicolumn{2}{|c|}{$-496.24 \pm 325.15$} & $0.36 \pm 0.74$ & 0.33 & 13.23 \\
\hline AM14 & \multicolumn{2}{|c|}{$71.62 \pm 35.87$} & \multicolumn{2}{|c|}{$-824.98 \pm 712.95$} & $-0.86 \pm 1.46$ & 0.43 & 18.64 \\
\hline
\end{tabular}

Notes - ${ }^{\mathrm{B}}$ Breeding, ${ }^{\mathrm{M}}$ Moulting. 
a

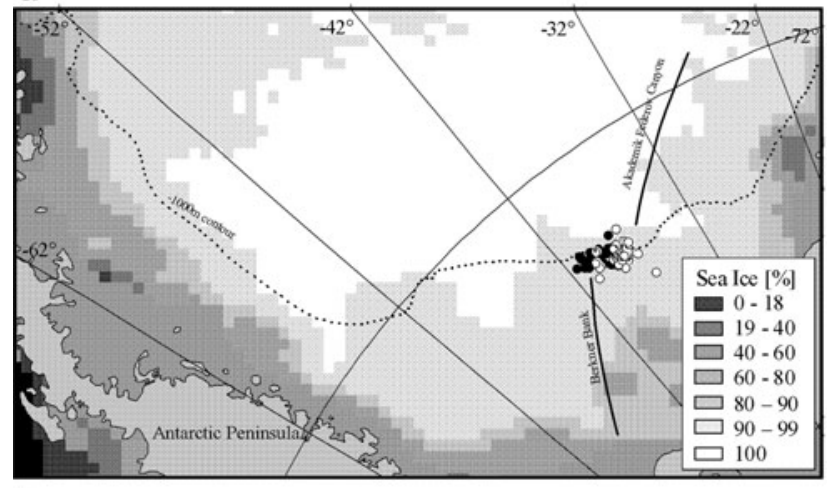

b

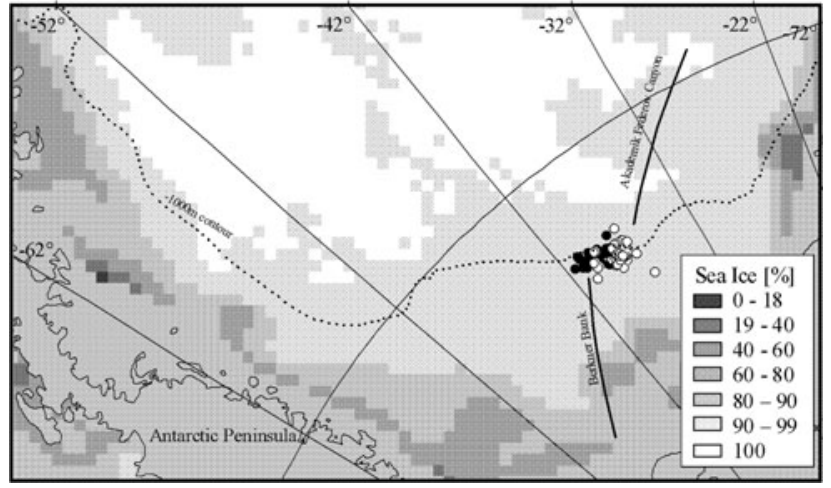

Fig. 3. Areas of restricted movement during the post-moult foraging trip for AM9 (-) and AM14 (-○), southern elephant seals from King George Island, during a. June, and b. August, the start and end of the foraging trips, the interim locations are included and do not vary from the locations recorded in June and August. The bathymetric features and $-1000 \mathrm{~m}$ contour are indicated on the maps.

(Fig. 1a). AM3 encountered shallow depths at all locations, sea ice concentrations were low and constant, and sea surface temperatures also showed little variability (Table I).

Two animals (AM8, AM13) moved to the north of King George Island, spending considerable periods of time to the east of Elephant Island (Fig. 1a). AM8 travelled further north than AM13 and encountered warmer waters and less sea ice than AM13 (Table I). Both animals encountered shallow waters (Table I).

Two animals (AM6, AM11) displayed a tendency to forage within the topographically heterogeneous environment of the Antarctic Peninsula (Fig. 1a). Neither of these animals moved further than $550 \mathrm{~km}$ from King George Island. Both animals never utilized depths greater than $-800 \mathrm{~m}$. Sea surface temperatures were low but constant (Table I). AM11 encountered up to $40 \%$ more sea ice than AM6, probably due to the fact that he moved further west than AM6. A post-breeding trip was recorded for AM11. Movements during the post-breeding period were similar to those displayed during the post-moult period. A period of ARM was recorded during this trip;

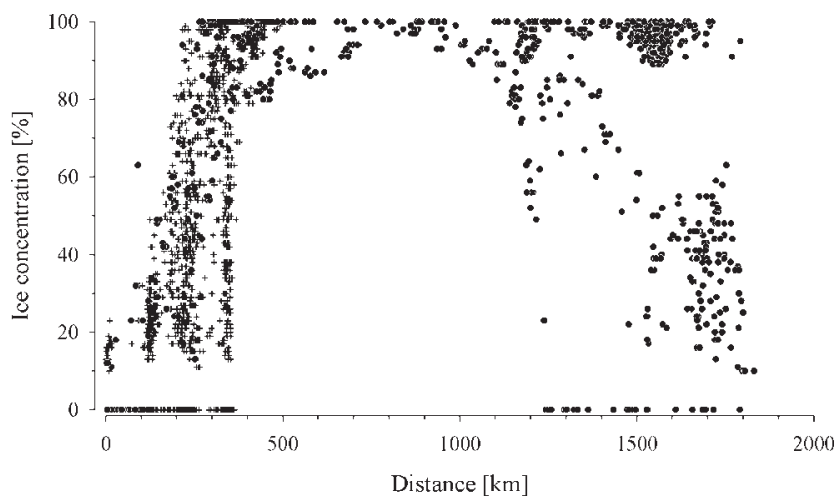

Fig. 4. Distances of all locations $(n=4828)$ of eight adult male elephant seals, coded by $(+)$ for animals that faced low to intermediate sea ice conditions and smaller distances relative to King George Island (AM3, AM6, AM8, AM11, AM13), and (O) for animals that moved into the southern Weddell Sea (AM9, AM10, AM14) where ice concentrations were high.

movements during this period were more variable than the post-breeding ARM (Fig. 2). Locations recorded during transit were compared to locations recorded during ARM for AM11. There were no significant differences in terms of sea ice concentration, depth or sea surface temperature. There was a significant difference in terms of swim speed, with ARM swim speeds being significantly lower than transit swim speeds (Sign test: $\mathrm{Z}=2.46 ; P=0.0139$ ).

The three remaining animals (AM9, AM10, AM14) travelled into the Weddell Sea moving along the shelf margin east of the Antarctic Peninsula, until they reached their southernmost positions at approximately $75^{\circ} \mathrm{S}$, a bathymetrically heterogeneous region (Berkner Bank, Akademik Fedorov Canyon and the Filchner Trough) (Fig. 1b). Movements through this region were characterized by high sea ice concentrations, varied bathymetry, as well as cold sea-surface temperatures, resulting in high variability for sea surface temperatures encountered throughout the recorded tracks (Table I). The regions in which ARM was recorded were adjacent to the dense pack ice that exists in the middle of the Weddell Sea (Fig. 3). An animation of sea ice cover and seal locations visualizes seal movements relative to overall sea ice distribution in a daily time series from March 2000 to March 2001 (Martin et al. 2006). This indicates substantial differences between winter and summer ice conditions in the southern Weddell Sea resulting in very high and low to intermediate sea ice concentrations during the respective ARMs (Fig. 4). AM9 remained in a localized $100 \mathrm{~km}$ wide shelf-slope area between the Berkner Bank and the Akademik Fedorov Canyon for 102 days. On 25 August the seal headed north through heavy pack ice to South Georgia to breed; last transmissions were received from the southernmost tip of the island on 23 October 2000. AM14 travelled on a path remarkably similar to that of AM9, 
arriving 22 days later (26 May) at exactly the same localized area between the Berkner Bank and the Akademik Fedorov Canyon and remained there for 100 days. On 3 September AM14 moved back to King George Island for the breeding season and embarked on a post-breeding journey to approximately the same area as his post-moult trip. It remained in this area for 63 days $(24$ December-25 February) in a large coastal polynya and then returned to King George Island to moult, before transmissions ended on 20 March 2001 (Fig. 1b).

\section{Discussion}

Adult male elephant seals instrumented on King George Island in 2000 displayed different movements compared to female southern elephant seals instrumented on the same island in 1997 (Bornemann et al. 2000). Female elephant seals travelled to the area west of the Antarctic Peninsula in 1997 (Bornemann et al. 2000). It is difficult to explain the possible reasons for their different travel patterns, especially since individuals of both sexes were not instrumented during the same time period. This makes it difficult to uncover whether observed behaviours are in response to environmental conditions or if large amounts of individual variation within a relatively small sample of animals are being observed. Continued instrumentation of animals is necessary to see if these differential migratory patterns are persistent over time and if sexual segregation of foraging areas actually does exist.

Quantifying movement variation allows for the comparison of movements between different areas of restricted movement catalogued during a track (Tremblay et al. 2007). For example, AMs 11 and 14 both showed higher movement variation indices during the post-breeding areas of restricted movement than post-moult areas of restricted movement (Fig. 2). Seasonal variation in foraging behaviour, based on diving characteristics, has been described for animals from South Georgia (Bennet et al. 2001). This variation could arise from: 1) seasonality in the distribution of resources, 2) metabolic constraints (Bennet et al. 2001), or in this case, 3) from restricted access to breathing holes/cracks due to higher sea ice concentrations during the post-moult trip, which generally occurred in the late autumn and early winter. The collection of good quality tracks over time and the quantification of mass gain for animals travelling to different areas would help to evaluate the potential benefits of utilizing different foraging areas. Quantifying movement variation allows for comparison between populations and would prove valuable in evaluating the effects of dynamic oceanographic variables on the movements of these animals.

The environmental variables that were investigated in this study fall into two categories, namely static variables, such as bathymetry, and dynamic variables that vary continuously over space and time. These dynamic variables appear to be the biggest constraint in modelling marine habitat suitability (Skov et al. 2008). It is impossible to generalize to the whole population from a few animals instrumented in a particular year that display a large amount of individual variation. A few animals avoided sea ice altogether and others seemed to exploit the increased primary productivity that is associated with fragmented sea ice and ice edges (Bargagli 2005). The tendency to feed along the continental shelf does not seem to be unique to elephant seals from King George Island. Animals from South Georgia (McConnell \& Fedak 1996) and Patagonia (Campagna et al. 1999) also displayed the tendency to feed close to their respective haulout areas and made use of shallow, localized feeding areas along the respective shelf margins.

The movements of AM8 and AM13 may not be unique, as similar results have been found for animals instrumented at Elephant Island in 1999 (Muelbert et al. 2004). Both findings coincide with the area just to the north of the Antarctic Peninsula, where the Antarctic Circumpolar Current is directed through the Drake Passage into the Scotia Sea (Holm-Hansen et al. 2004). The results of the present study show that at least three of the eight animals preferred the steep continental slope areas far south in the Weddell basin during the study period. Here, the southern branch of the Weddell Gyre meets the Filchner Trough outflow, which together with the rough bathymetry causes intensive mixing of the contributing water masses.

The particular region utilized by AM9 and AM14 corresponds closely with the region identified by Foldvik et al. (2004) as being important for the production of Weddell Sea Bottom Water (WSBW). The production of WSBW is important for the export of Antarctic Bottom Water (AABW), the water body along which cold, dense and oxygenated water is exported from the Antarctic to the surrounding oceans. This area is also characterized by elevated trace element concentrations dissolved from the shelf ice into the Ice Shelf Water. This water mass is transported to the north through the Filchner Trough into the Weddell Gyre circulation system where it is heavily mixed within the Antarctic Slope Front. The Filchner outflow is one of, if not the only, steady annual source of shelf water that is responsible for the deep water and bottom water production in the Weddell Sea. The restricted area movements displayed in this region illustrate a connection between important physical oceanographic features and biological processes of a top-level predator.

The tendency of southern elephant seals to forage on the Antarctic Continental Shelf, within the pack ice, has been illustrated for seals from Iles Kerguelen (Bailleul et al. 2007) and Macquarie Island (Bradshaw et al. 2003). Weddell seal foraging behaviour has been linked to the presence of the Antarctic silverfish (Pleuragramma antarcticum Boulenger) in the Weddell Sea (Plötz et al. 2001). The presence of this fish, a dominant pelagic 
species (Hubold 1985), has also been suggested to influence the movement patterns of female elephant seals (Bornemann et al. 2000) - and forms an important part of the pelagic fish diet of southern elephant seals from King George Island (Daneri \& Carlini 2002). The presence of the Antarctic silverfish in the ice-bound Weddell Sea has been linked to the high densities of krill, Euphausia superba Dana, that congregate under ice sheets and take advantage of melting ice releasing algae into underlying water bodies (Stretch et al. 1988). Given that male southern elephant seals perform both benthic and pelagic foraging dives (Hindell et al. 1991), a pattern also observed for juvenile and adult male northern elephant seals (Le Boeuf et al. 1996), the presence of $P$. antarcticum may explain the tendency of male southern elephant seals from King George Island to travel through dense pack ice into high Antarctic latitudes in order to find an abundant food source.

\section{Outlook}

The Intergovernmental Panel on Climate Change (IPCC) predicts that climate change will influence changes in temperature, which in turn will influence ocean circulation, ice coverage and sea levels (McCarthy et al. 2001). All these factors, often associated with broad-scale climate change, can have immediate and direct impacts on marine mammals by influencing food availability. At present, the link between seal population numbers and environmental conditions remains tentative (Sun et al. 2004), especially in terms of directionality. Climate cooling may cause sea ice cover to increase, protecting biotas that are able to survive under the ice from top-level predators such as whales and seals. Conversely, climate warming may cause a reduction in sea ice cover, increasing primary and secondary production and providing access for top-level predators through the creation of breathing holes. This research shows the dependence of male southern elephant seals from King George Island on ocean circulation systems, such as the Weddell Gyre, as well as an intimate association of these animals with sea ice. Populations of these animals can easily be monitored owing to their terrestrial breeding habits, fidelity to natal sites and large body sizes and are thus ideal climate change monitoring species (Simmonds \& Isaac 2007).

\section{Acknowledgements}

The seal studies were done as part of an international agreement between Germany and Argentina, and carried out by South African (MRI), Argentinean (IAA), and German (AWI) partners at the Dallmann Laboratory, Jubany Station, King George Island, Antarctica. The University of Pretoria, the South African National Antarctic Program (SANAP), the National Research Foundation (NRF) and Department of Science and Technology (DST) are thanked for their financial support. M.N. Bester would like to thank the University of Pretoria for providing leave to work at King George Island. The authors owe special thanks to the Argentinean team colleagues and the staff of the Jubany Station for the good collaboration, helpful support, their friendship and hospitality. The authors would like to thank M.A. Fedak and J. van den Hoff for their valuable comments on the paper.

\section{References}

Bailleul, F., Charrassin, J.B., Ezraty, R., Girard-Ardhuin, F., McMahon, C.R., Field, I.C. \& Guinet, C. 2007. Southern elephant seals from Kerguelen Islands confronted by Antarctic Sea ice. Changes in movements and behaviour. Deep Sea Research II, 54, 343-355.

BARGAGLI, R. 2005. The southern ocean environment: anthropogenic impact and climate change. In Caldwell, M.M., Heldmaier, G., Jackson, R.B., Lange, O.L., Mooney, H.A., Schulze, E.D. \& Sommer, U., eds. Antarctic ecosystems. Berlin: Springer, 102-116.

Bennet, K.A., McConnell, B.J. \& FedaK, M.A. 2001. Diurnal and seasonal variations in the duration and depth of the longest dives in southern elephant seals (Mirounga leonina): possible physiological and behavioural constraints. Journal of Experimental Biology, 204, 649-662.

Biuw, M., Boehme, L., Guinet, C., Hindell, M., Costa, D., Charrassin, J.B., Roquet, F., Bailleul, F., Meredith, M., Thorpe, S., Tremblay, Y., McDonald, B., Park, Y.H., Rintoul, S.R., Bindhoff, N., Goebel, M., Crocker, D., Lovell, P., Nicholson, J., Monks, F. \& Fedak, M.A. 2007. Variations in behaviour and condition of a southern ocean top predator in relation to in situ oceanographic conditions. Proceedings of the National Academy of Sciences, 104, 13705-13710.

BLock, B.A. 2005. Physiological ecology in the 21 st century: advancements in biologging science. Integrative and Comparative Biology, 45, 305-320.

Bornemann, H., Kreyscher, M., Ramdohr, S., Martin, T., Carlini, A., Sellmann, L. \& Plötz, J. 2000. Southern elephant seal movements and Antarctic sea ice. Antarctic Science, 12, 3-15.

Bradshaw, C.J.A., Hindell, M.A., Best, N.J., Phillips, K.L., Wilson, G. \& Nichols, P.D. 2003. You are what you eat: describing the foraging ecology of southern elephant seals (Mirounga leonina) using blubber fatty acids. Proceedings of the Royal Society of London, B270, 1283-1292.

Bradshaw, C.J.A., Hindell, M.A., Michael, K.J. \& Sumner, M.D. 2002. The optimal spatial scale for the analysis of elephant seal foraging as determined by geo-location in relation to sea surface temperatures. ICES Journal of Marine Science, 59, 770-781.

Campagna, C., Fedak, M.A. \& McConnell, B.J. 1999. Post-breeding distribution and diving behaviour of adult male southern elephant seals from Patagonia. Journal of Mammalogy, 80, 1341-1352.

Campagna, C., Piola, A.R., Martin, M.R., Lewis, M. \& Fernández, T. 2006. Southern elephant seal trajectories, fronts and eddies in the Brazil/ Malvinas confluence. Deep-Sea Research I, 53, 1907-1924.

Campagna, C., Piola, A.R., Martin, M.R., Lewis, M., Zajaczkovski, U. \& FERNÁNDEZ, T. 2007. Deep divers in shallow seas: southern elephant seals on the Patagonian shelf. Deep-Sea Research I, 54, 1792-1814.

Campagna, C., Rivas, A.L. \& Martin, M.R. 2000. Temperature and depth profiles recorded during dives of elephant seals reflect distinct ocean environments. Journal of Marine Systems, 24, 299-312.

Carlini, A.R., Daneri, G.A., Márquez, M.E.I., Bornemann, H., Panarello, H., Casaux, R., Ramdohr, S. \& Plötz, J. 2005. Food consumption estimates of southern elephant seal females during their post-breeding aquatic phase at King George Island. Polar Biology, 28, 769-775.

Carlini, A.R., Daneri, G.A., Márquez, M.E.I., Soave, G.E. \& Poljak, S. 1997. Mass transfer from mothers to pups and mass recovery by mothers during the post-breeding foraging period in southern elephant seals (Mirounga leonina) at King George Island. Polar Biology, 18, $305-310$. 
Cavalieri, D., Parkinson, P., Gloerson, P. \& Zwally, H.J. 1996 (updated 2006). Sea ice concentrations from Nimbus-7 SMMR and DMSP SSM/I passive microwave data, (2000-2001). Boulder, CO: National Snow and Ice Data Centre. Digital media.

Daneri, G.A. \& Carlini, A.R. 2002. Fish prey of southern elephant seals, Mirounga leonina, at King George Island. Polar Biology, 25, $739-743$.

Galimberti, F., Sanvito, S., Braschi, C. \& Boitani, L. 2007. The cost of success: reproductive effort in male southern elephant seals (Mirounga leonina). Behavioural Ecology and Sociobiology, 62, 159-171.

Gregr, E.J. \& Bodtker, K.M. 2007. Adaptive classification of marine ecosystems: identifying biologically meaningful regions in the marine environment. Deep Sea Research 1, 54, 385-402.

FEDAK, M.A. 2004. Marine animals as platforms for oceanographic sampling: a "win/win" situation for biology and operational oceanography. Memoirs of the National Institute of Polar Research, 58, $133-147$.

Field, I., Hindell, M., Slip, D. \& Michael, K. 2001. Foraging strategies of southern elephant seals (Mirounga leonina) in relation to frontal zones and water masses. Antarctic Science, 13, 371-379.

Foldvik, A., Gammelsrød, T., Østerhus, S., Fahrbach, E., Rohardt, G., Schröder, M., Nicholls, K.W., Padman, L. \& Woodgate, R.A. 2004. Ice shelf water overflow and bottom water formation in the southern Weddell Sea. Journal of Geophysical Research 109, 10.1029/ 2003JC002008.

Hindell, M.A., Burton, H.R. \& Slip, D.J. 1991. Foraging areas of southern elephant seals, Mirounga leonina, as inferred from water temperature data. Australian Journal of Marine and Freshwater Research, 42, 15-128.

Hindell, M.A., Bradshaw, C.J.A., Sumner, M.D., Michael, K.J. \& Burton, H.R. 2003. Dispersal of female southern elephant seals and their prey consumption during the austral summer: relevance to management and oceanographic zones. Journal of Applied Ecology 40, 703-715.

Hindell, M.A. \& Little, G.J. 1988. Longevity, fertility and philopatry of two female southern elephant seals (Mirounga leonina) at Macquarie Island. Marine Mammal Science, 4, 168-171.

Holm-Hansen, O., Kahru, M., Hewes, C.D., Kawaguchi, S., Kameda, T., Sushin, V.A., Krasovski, I., Priddle, J., Korb, R., Hewitt, R.P. \& Mitchell, B.G. 2004. Temporal and spatial distribution of chlorophyll- $a$ in surface waters of the Scotia Sea as determined by both shipboard measurements and satellite data. Deep-Sea Research II, 51, $1323-1331$.

Hubold, G. 1985. Stomach contents of the Antarctic silverfish Pleuragramma antarcticum from the southern and eastern Weddell Sea (Antarctica). Polar Biology, 5, 43-48.

IOC, IHO \& BODC. 2003. Centenary edition of the GEBCO Digital Atlas, Intergovernmental Oceanographic Commission and the International Hydrographic Organisation, General Bathymetric Chart of the Oceans. Liverpool: British Oceanographic Data Centre, CD-ROM.

JonKer, F.C. \& BESTER, M.N. 1998. Seasonal movements and foraging areas of adult southern female elephant seals, Mirounga leonina, from Marion Island. Antarctic Science, 10, 21-30.

Le Boeuf, B.J. \& Laws, R.M. 1994. Elephant seals: an introduction to the genus. In Le Boeuf, B.J. \& Laws, R.M., eds. Elephant seals: population ecology, behavior and physiology. Berkley, CA: University of California Press, 1-26.

Le Boeuf, B.J., Morris, P.A., Blackwell, S.B., Crocker, D.E. \& Costa, D.P. 1996. Diving behaviour of juvenile northern elephant seals. Canadian Journal of Zoology, 74, 1632-1644.

Le Boeuf, B.J., Crocker, D.E., Costa, D.P., Blackwell, S.B., WebB, P.M. \& Houser, D.S. 2000. Foraging ecology of northern elephant seals. Ecological Monographs, 70, 353-382.

Lombard, A.T., Reyers, B., Schonegevel, L.Y., Cooper, J., Smith-Adao, L.B., Nel, D.C., Froneman, P.W., Ansorge, I.J., Bester, M.N., Tosh,
C.A., Strauss, T., Akkers, T., Gon, O., Leslie, R.W. \& Chown, S.L. 2007. Conserving pattern and process in the Southern Ocean: designing a marine protected area for the Prince Edward Islands. Antarctic Science, 19, 39-54.

Martin, T., Ramdohr, S., Plötz, J., Bornemann, H., Bester, M.N., Carlini, A.R., Sellmann, L. 2006. Animation of male southern elephant seal movements in relation to Antarctic sea ice cover. http://doi.pangea.de/ 10.1594/PANGAEA.509404

MCCANN, T.S. 1981. Aggression and sexual activity of male southern elephant seals, Mirounga leonina. Journal of Zoology, 195, 295-310.

McCarthy, J.J., Canziani, O.F., Leary, N.A., Dokken, D.J. \& White, K.S., eds. 2001. Climate change 2001: impacts, adaptation and vulnerability. Contribution of working group II to the third assessment report of the Intergovernmental Report of the Intergovernmental Panel on Climate Change. Cambridge: Cambridge University Press, 1042 pp.

McConnell, B.J., Chambers, C. \& Fedak, M.A. 1992. Foraging ecology and southern elephant seals in relation to bathymetry and productivity of the Southern Ocean. Antarctic Science, 4, 393-398.

McConnell, B.J. \& FedaK, M.A. 1996. Movements of southern elephant seals. Canadian Journal of Zoology, 74, 1485-1496.

McMahon, C.R., Bester, M.N., Burton, H.R., Hindell, M.A. \& Bradshaw, C.J.A. 2005. Population status, trends and a re-examination of the hypotheses explaining recent declines of the southern elephant seal Mirounga leonina. Mammal Review, 35, 82-100.

Muelbert, M.M.C., Robaldo, R.B., Martínez, P.E., Colares, E.P., Bianchini, A. \& Setzer, A. 2004. Movement of southern elephant seals (Mirounga leonina L.) from Elephant Island, South Shetlands, Antarctica. Brazilian Archives of Biology and Technology, 47, 461-467.

Otis, D.L. \& Whіте, G.C. 1999. Autocorrelation of location estimates and the analysis of radio-tracking data. Journal of Wildlife Management, 63, 1039-1044.

Pistorius, P.A., Bester, M.N., Lewis, M.N., Taylor, F.E., CAmpagna, C. \& KiRKMan, S.P. 2004. Adult female survival, population trend, and implications of early primiparity in a capital breeder, the southern elephant seal (Mirounga leonina). Journal of Zoology, 263, 107-119.

Plötz, J., Bornemann, H., Knust, R., Schröder, A. \& Bester, M.N. 2001. Foraging behaviour of Weddell seals, and its ecological implications. Polar Biology, 24, 901-909.

Ramdohr, S., Bornemann, H., Plötz, J. \& Bester, M.N. 2001. Immobilization of free ranging adult male southern elephant seals (Mirounga leonina) with Immobilon (etorphine/acepromacine) and ketamine. South African Journal of Wildlife Research, 3 \& 4, $135-140$.

Reynolds, R.W., Rayner, N.A., Smith, T.M., Stokes, D.C. \& Wang, W. 2002. An improved in situ and satellite SST analysis for climate. Journal of Climate, 15, 1607-1652.

Sale, P.F., Cowen, R.K., Danilowicz, B.S., Jones, G.P., Kritzer, J.P., Lindeman, K.C., Planes, S., Polunin, N.V.C., Russ, G.R., Sadovy, Y.J., StENECK, R.S. 2005. Critical science gaps impede use of no-take fishery reserves. Trends in Ecology and Evolution, 20, 74-80.

SCAR. 2000. Report of the Meeting of the Scientific Committee on Antarctic Research, Group of Specialists on Seals, Tokyo. http://www.seals.scar. org/pdf/meetings.pdf. 55-79.

Schaffer, S.A., Tremblay, Y., Weimerskirch, H., Scott, D., Thompson, D.R., Sagar, P.M., Moller, H., Taylor, G.A., Foley, D.G., Block, B.A. \& CostA, D.P. 2006. Migratory shearwaters integrate oceanic resources across the Pacific Ocean in an endless summer. Proceedings of the National Academy of Sciences, 103, 12799-12802.

Simmonds, M.P. \& IsAaC, S.J. 2007. The impacts of climate change on marine mammals: early signs of significant problems. Oryx, 41, $19-26$.

Skov, H., Humphreys, E., Garthe, S., Geitner, K., Grémillet, D., Hamer, K.C., Hennicke, J., Parner, H. \& Wanless, S. 2008. Application of habitat suitability modelling to tracking data of marine animals as a means of analyzing their feeding habits. Ecological Modelling, 212, 504-512. 
Stretch, J.J., Hamner, P.P., Michel, W.C., Cook, J. \& Sullivan, C.W. 1988. Foraging behaviour of Antarctic krill Euphausia superba on sea ice microalgae. Marine Ecology Progress Series, 44, 131-139.

Sun, L., Liu, X., Yin, X., Zhu, R., Xie, Z. \& WANG, Y. 2004. A 1,500-year record of Antarctic seal populations in response to climate change. Polar Biology, 27, 495-501.

Tremblay, Y., RoBerts, A.J. \& CostA, D.P. 2007. Fractal landscape method: an alternative approach to measuring area-restricted searching behavior. Journal of Experimental Biology, 210, 935-945.
Van den Hoff, J., Burton, H.R., Hindell, M.A., Sumner, M.D. \& McMahon, C.R. 2002. Migrations and foraging of juvenile southern elephant seals from Macquarie Island within CCAMLR managed areas. Antarctic Science, 14, 134-145.

White, N.A. \& SJöBerg, M. 2002. Accuracy of satellite positions from free-ranging grey seals using ARGOS. Polar Biology, 25, 629-631.

Wilkinson, I.S. \& Bester, M.N. 1990. Duration of post-weaning fast and local dispersion in the southern elephant seal, Mirounga leonina, at Marion Island. Journal of Zoology, 222, 591-600. 